Les ANNALES Les Annales de droit

DE DROIT

$14 \mid 2020$

Varia

\title{
Douzième chameau, douzième lecture et... quatorzième numéro
}

\section{Christophe Otero}

\section{(2) OpenEdition}

1 Journals

Édition électronique

URL : https://journals.openedition.org/add/1746

DOI : $10.4000 /$ add. 1746

ISSN : 2606-1988

\section{Éditeur}

Presses universitaires de Rouen et du Havre

\section{Édition imprimée}

Date de publication : 1 juin 2020

Pagination : 7-8

ISBN : 979-10-240-1442-5

ISSN : 1955-0855

\section{Référence électronique}

Christophe Otero, "Douzième chameau, douzième lecture et... quatorzième numéro », Les Annales de droit [En ligne], 14 | 2020, mis en ligne le 01 juin 2021, consulté le 14 janvier 2023. URL : http:// journals.openedition.org/add/1746; DOI : https://doi.org/10.4000/add.1746

Ce document a été généré automatiquement le 14 janvier 2023.

Tous droits réservés 


\title{
Douzième chameau, douzième lecture et... quatorzième numéro
}

\author{
Christophe Otero
}

1 François Ost, dans un article célèbre, relate un récit, relatif à un partage successoral $a$ priori insoluble d'un troupeau de onze chameaux entre trois fils, et il en propose douze lectures possibles (approches mathématique, psychologique, juridique, biblique, etc.) In fine, il admet ceci :

le propos de cette courte réflexion, le lecteur s'en est rendu compte, est le produit d'un travail résolument interdisciplinaire. Il résulte aussi, outre de lectures académiques classiques, de nombreuses discussions informelles dont l'auteur a pu bénéficier avec des collègues et amis, grâce notamment au courrier électronique. Au cours des mois qui ont précédé la rédaction de ce texte, le douzième chameau a beaucoup voyagé sur les pistes de l'Internet et dans le no man's land entre les disciplines. Ce type d'échanges me parait très exactement le meilleur de ce que peut offrir la recherche scientifique. Peut-être celle-ci, toujours menacée d'enfermement dans ses partages disciplinaires, a-t-elle, elle aussi besoin, d'un douzième chameau pour progresser ${ }^{1}$ ?

2 Les auteurs, les membres du comité scientifique et ceux du comité de rédaction, les lecteurs se reconnaitront dans ces quelques lignes relatives à la rédaction, à l'échange, à la confrontation des idées et à l'évolution - autant que l'amélioration - du propos. S'opère ainsi un condensé de ce qui fait le lien intellectuel dans la recherche, mais qui surtout fait lien sur le plan humain. Collaborer pour uniquement publier un numéro de plus à une collection déjà riche n'aurait guère d'intérêt et peu de sens. Le projet et sa réalité dépassent fort heureusement le seul aspect matériel d'une énième addition à une énième édition. Ils se distancient aussi des seules contingences pécuniaires, l'intérêt de la recherche scientifique dans les sciences humaines et sociales s'accorde (trop ?) bien avec le désintéressement financier. Ils mobilisent finalement bien davantage les ressorts de l'appétence et de la valorisation : le goût pour la recherche des uns et des autres, l'exposition de la production d'auteurs diversifiés. 
3 Dans sa dernière approche, l'auteur avoue humblement « Douzième lecture ? La vôtre, évidemment, cher lecteur; la meilleure assurément "(ibid., p. 866). Nous offrons à votre lecture, tout aussi modestement, ce quatorzième numéro.

\section{NOTES}

1. «Le douzième chameau ou l'économie de la justice », Liber amicorum Guy Horsmans, Bruxelles, Bruylant, 2004, p. 867.

\section{AUTEUR}

\section{CHRISTOPHE OTERO}

Pour le comité de rédaction 